\title{
COMPARATIVE NUMERICAL ANALYSES OF A REINFORCED CONCRETE STRUCTURE UNDER SEISMIC ACTION
}

\author{
Fadhila Hasnaoui, Luc Davenne
}

Laboratoire Energétique Mécanique Electromagnétisme, Université Paris-Ouest Nanterre La Défense.France. (fadhila.hasnaoui@u-paris10.fr, luc.davenne@u-paris10.fr)

\begin{abstract}
Numerical procedures for predicting reinforced concrete $(R C)$ frames behavior, subjected to severe solicitation in particular earthquake, is nowadays a very important challenge in earthquake engineering field. The development of finite element (FE) codes generated multiple models of discretization associated to various rules of concrete and steel materials behavior. Indeed, both the coupling of these highly heterogeneous materials requires a fairly extensive behavior study including a maximum of parameters for better structure response simulation under seismic actions. Although, theoretically the most satisfying RC frames seismic analysis model involves the application of inelastic time-history dynamic analysis of three dimensional model of RC frames. Nowadays, this model seems to be too expensive or impractical due to the structures size and complexity. However, the simplified models applied to nonlinear static method can offer a good damage and safety evaluation of buildings' dynamic behavior. Other aims for $R C$ structures seismic analysis are to be noticed, either for safety margins determination of the existing structures or the new buildings design. This work aims to expose the most used existing approaches in seismic numerical analysis and carry out a comparative study with the goal of evaluating the capacity of each method. Four models of seismic analyses are considered: dynamic, static, linear and nonlinear. Predictions are confronted with experimental results obtained from shake table tests. Furthermore, aiming to have a complete seismic analysis, three FE discretization models were studied for different scales. Hence, detailed knowledge of each approach was gotten from this procedure, deducing as a result the advantages and disadvantages of each model (reliability, computational time and domain of applicability), and providing a full database for reliability development and numerical methods robustness in earthquake, complying with the seismic design European standard recommendations. Comparing numerical and experimental results, a satisfying concordance is obtained when considering the initial structure damage. These results will be a good asset to assess the impact of uncertain parameters on seismic hazard and nonlinear response, through robust and simplified approach development of $R C$ structures vulnerability estimating in civil engineering.
\end{abstract}

Keywords: Reinforced concrete structures, seismic, finite element discretization, nonlinear, damage.

\section{INTRODUCTION}

The mechanical qualities and relatively low costs of concrete make it the most widely used material in construction, for all components from the foundations until the roof in 
general civil structures or in special constructions. In addition to these intrinsic qualities, the concrete is considered as a very heterogeneous material, thus, coupling with steel, the reinforced concrete materials become very complex to study. Optimal exploitation of these heterogeneous materials require a detailed knowledge of its various behavioral states: plasticity, damage in tension, opening / closing of cracks, plasticity of steel, etc. Nonetheless, a fairly extensive behavior study including a maximum of parameters for better structure response simulation seems to be too expensive or impractical due to the structures size and/or complexity of structures mainly under dynamic loading.

Numerical procedures for predicting reinforced concrete frames behavior, subjected to severe solicitation in particular earthquake, is nowadays a very important challenge in earthquake engineering field. The development of finite element codes generated multiple models of discretization associated to various rules of concrete and steel materials behavior. It should be noted that the choice of the analysis procedure to be adopted depends on several parameters, such as the importance of the structure, the performance level, the structural characteristics, the amount of data available for developing a structural model, etc. For that reason we expose in this work a multi-scales comparative study aiming to have a complete seismic analysis. Three FE discretization models were studied for different scales: local, semilocal and global. For each model of discretization we have associated four principal approaches for seismic analysis: dynamic, static, linear and nonlinear approach. Predictions are confronted with experimental results obtained from shake table tests [3] realised by Filiatrault in polytechnic school of Montreal.

Detailed knowledge of each approach was gotten from this work, deducing as a result the advantages and disadvantages of each model as: reliability, computational time, domain of applicability..., and providing a full database for reliability development and numerical methods robustness in earthquake, complying with the seismic design European standard recommendations.

\section{STRUCTURAL MODEL AND SPECIFIC SITE EARTHQUAKE INPUT}

The numerical test structure considered in this investigation consists in two-half scale $\mathrm{RC}$ frame with two bays and two storeys having each $2.5 \mathrm{~m}$ in width and $1.5 \mathrm{~m}$ in height. The structure design was done per National Building Code of Canada (NBCC 1995) and the Canadian Concrete Standard (CSA 1994); it is located in a seismic zone 4 in Canada. Geometry of structure, columns and beams longitudinal and transverse reinforcements are shown in figure 1.
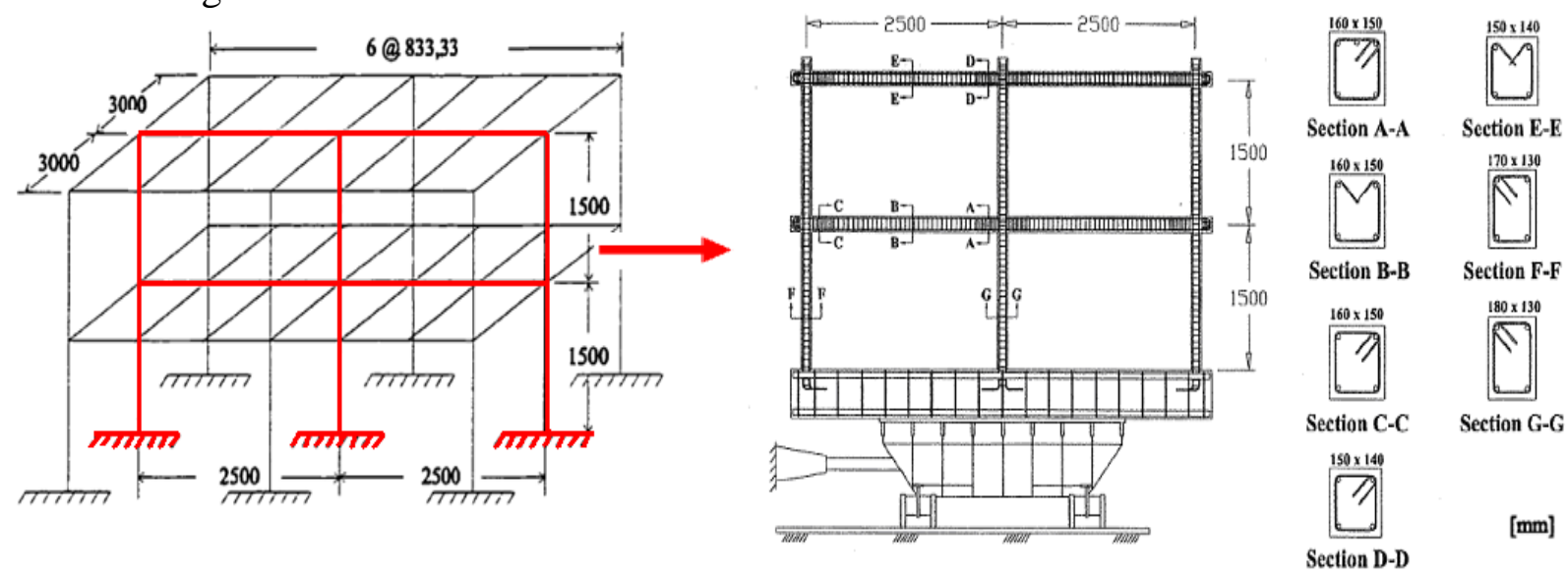

Figure 1. Details of test frame. 
The current design codes recommend selecting of at least three ground motion records for representation of the time-history acceleration. Although it is further prescribed that the spectral shape of selected ground motion records shall be in a good accordance with the design spectrum (elastic spectrum). In this study, Filiatrault et al. [3] have considered a selection of six historical earthquake accelerograms for the city of Vancouver (Canada). Figure 2, presents the acceleration time history for shake table signal used in this work.

The concrete parameters chosen for this computation are the same as those in [3].Young's modulus, $\mathrm{E}=25,210^{3} \mathrm{MPa}$, compressive strength, $\mathrm{F}_{\mathrm{y}}=31 \mathrm{MPa}$, and Poisson's coefficient, $v=0.17$. Reinforcement steel material is assumed to have the following properties: Young's modulus, $\mathrm{E}=224,610^{3} \mathrm{MPa}$, yield strength, $\mathrm{F}_{\mathrm{y}}=438 \mathrm{MPa}$, yield strain, $\varepsilon_{\mathrm{y}}=0.00195$, tensile strength $\mathrm{F}_{\mathrm{u}}=601 \mathrm{MPa}$ and ultimate strain $\varepsilon_{\mathrm{u}}=0.199$.

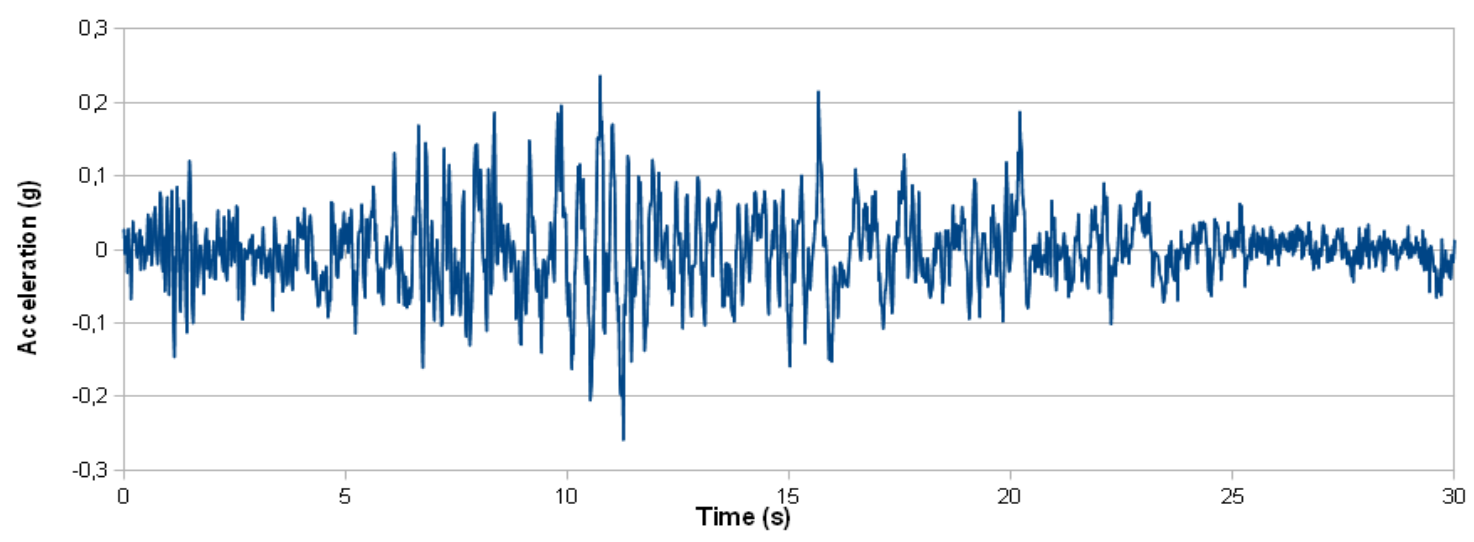

Figure 2. Feedback shake table time-history.

\section{STUDIED MODELS}

The aim of having a full comparative study on seismic behavior of a reinforced concrete structure, we discretized the frame following three scales: local (solid model), semilocal (multi-fiber model) and global (macro-element model).

Theoretical predictions of the response of the test frame were obtained using the computer program Cast3M [1]. Cast3M is a general Finite Element computer code for fluid and structural mechanics, it is developed by the "Département de Modélisation des Systèmes et Structures" (DM2S) of the "Direction de l'Énergie Nucléaire" of the French Alternative Energies and Atomic Energy Commission (CEA).

The different computations were performed on a machine with $4 \mathrm{CPU} 2.40 \mathrm{GHz}$ each.

\subsection{Solid model}

To understand the influence of local effects on overall response and the failure mechanism due to the highly nonlinearities, a detailed finite element analysis was carried out.

The concrete is discretized with cubical-solid elements composed of eight Gaussian integration points. Steel is modeled by two-node linear elements. A perfect bonding is considered between concrete and steel. The detailed model of solid 3D allows a good representation of the geometric structure and an improved kinematic approximation. Figure 3, shows the descretization of the studied frame. 


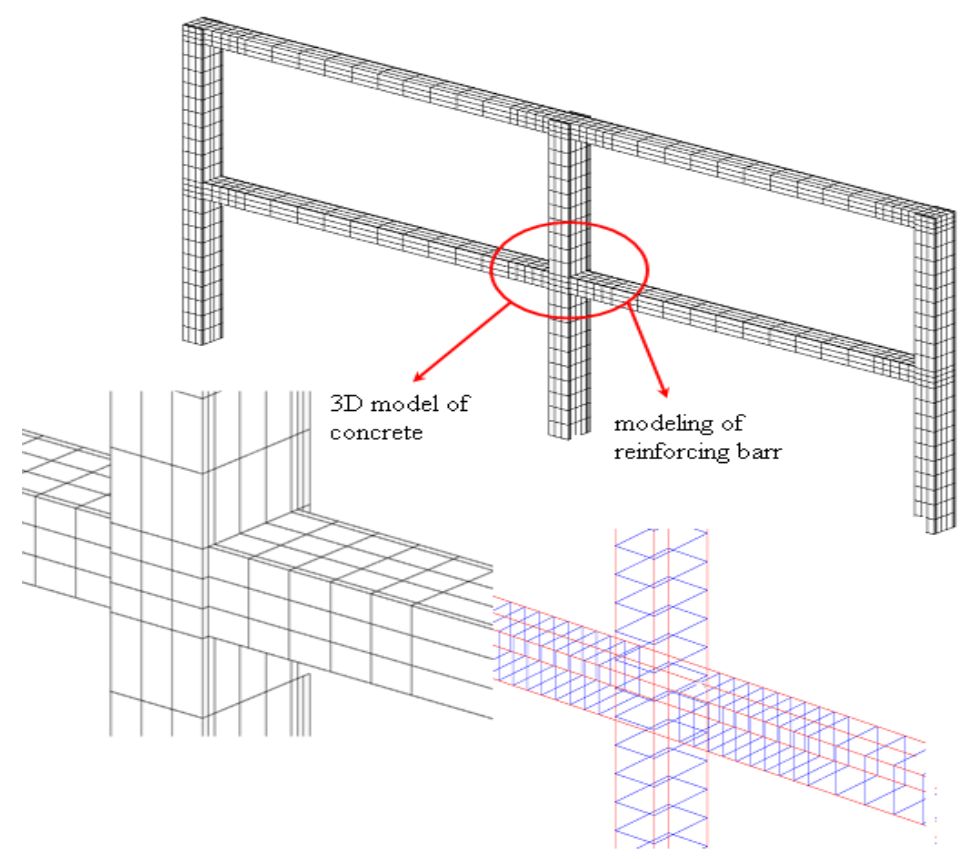

Figure 3. Solid model for studied frame.

\subsection{Multi-fiber model}

In this section, the frame is introduced as the fine micro scale beam model used to explore the details of inelastic constitutive behavior of material such as the reinforced concrete. The analysis of this kind is quite equivalent to nonlinear homogenization, which will provide the best possible definition of 'macro' stress resultant beam model. The building is modeled using Timoshenko multi-fiber beam elements. Constitutive material laws are based on damage mechanics for concrete and plasticity for steel. The Timoshenko multi-fiber beam element and the damage mechanic law have been implemented in Cast3M code. Mesh details are given in Figure 4.The beam rectangular cross-section is divided into a number of concrete fibers and reinforced fibers. The optimal number of concrete fibers is determined based on the bilinear moment-curvature response for a beam element.

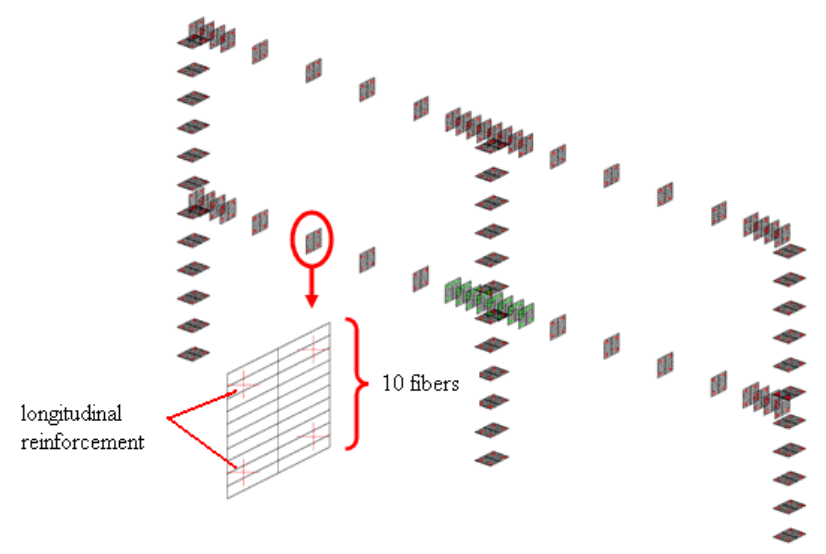

Figure 4. The fiber beam-column model.

\subsection{Macro-element model}


The macro-element approach consists in condensing all geometric and material nonlinearities into a finite domain and works with generalized variables, forces and displacements. The general structural model of studied structure is illustrated in figure 5. A bilinear inelastic moment-curvature relation was implemented for each structural member. A simplified rule for reinforced concrete behavior of modified Takeda model (Otani; 1974) was used to simulate the moment curvature behavior of all members [1].

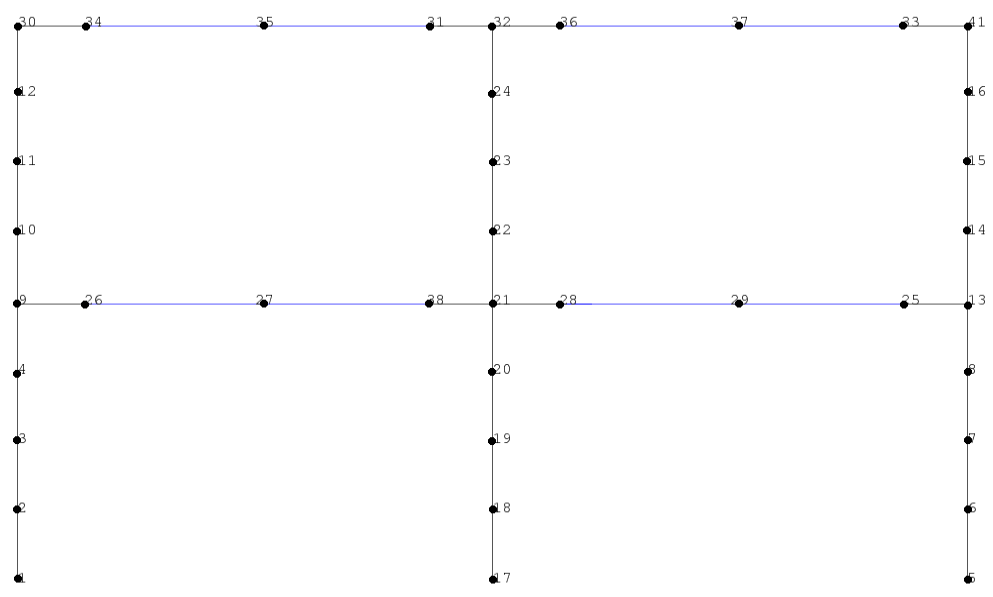

Figure 5. Macro-element mesh.

\section{PRELIMENARY ANALYSES}

\subsection{Cracking patterns}

For many reinforced concrete cross-sections, the spread of plasticity starting from the ends of the members along the length is not very significant and the deformation is concentrated at or near the cross-sections ends [4]. Therefore, we will assume that the plasticity is concentrated at the end cross-section. We also assume that the end cross sections is suddenly plastified and that the material behaves in a perfectly elastic-plastic manner.

It should be noted that the introduction of additional weights on the beams caused damage to the overall structure [5]. Cracking patterns are remarkable especially in the beams due to the presence of bending and at the central joint on the first floor due to apparition of torsion, see figure 6. These findings indicate the occurrence of damage before dynamical testing causing a significant loss of structural stiffness. Therefore, this work has been done in two phases: (1) seismic computations with initial stiffness; and (2) seismic computations with reduced stiffness. 


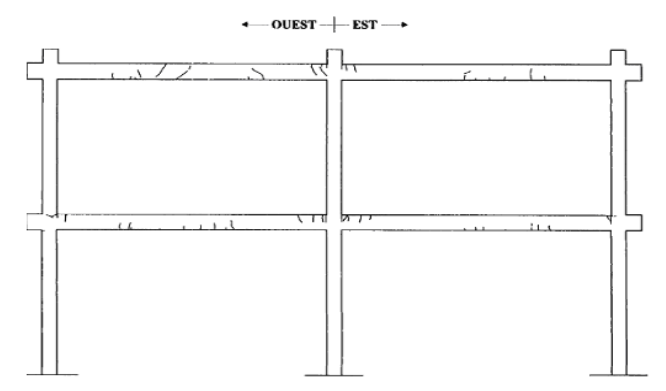

experimental result

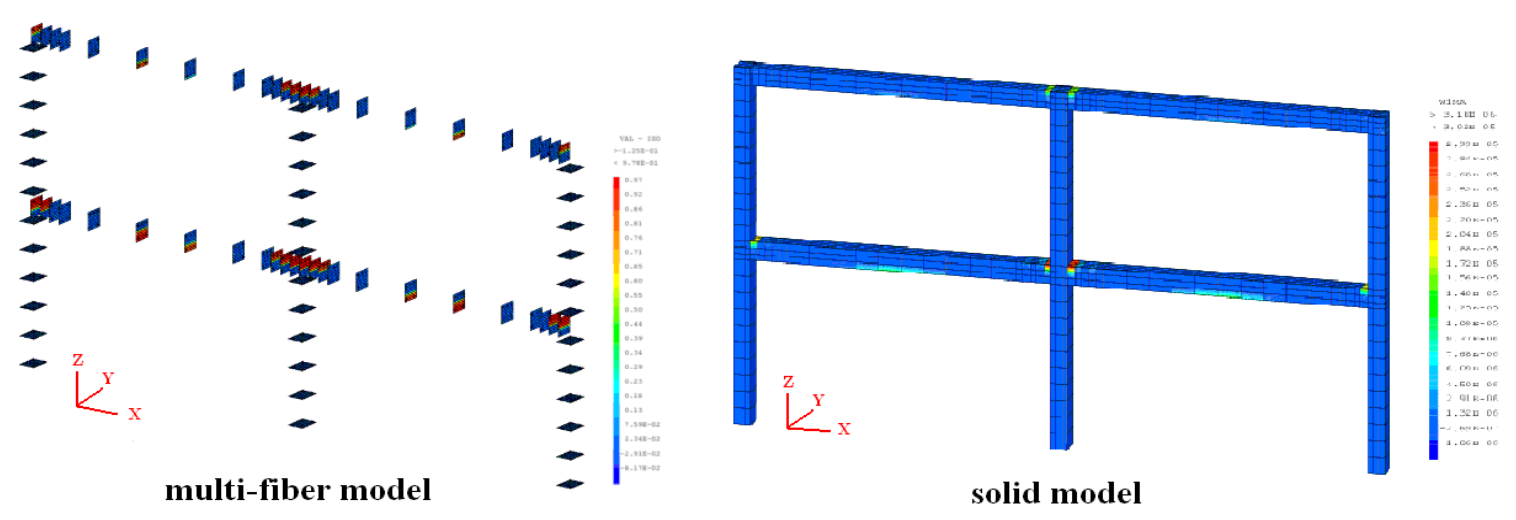

Figure 6. Cracking patterns of test structure before seismic test.

\subsection{Modal analysis}

To simulate concentrated gravity loads, four concrete blocks were being attached in the central third portion of the beams. Numerically, the inertia effects of the additional masses were accounted by specifying a density for each block element. The total weight of frame was $96 \mathrm{kN}$. The numerical calculation does not take into account neither the modeling of the foundation nor the shaking table, thus, columns are fixed at the bases. The natural periods of the test structures are calculated for the initial and reduced stiffness. Results of frequencies and periods are presented in the following table.

Table 1. Frequencies and period for different model

\begin{tabular}{|c|c|c|c|c|c|c|c|c|c|c|c|}
\hline & \multirow{2}{*}{\multicolumn{2}{|c|}{$\begin{array}{l}\text { Experimental } \\
\text { results }\end{array}$}} & \multicolumn{9}{|c|}{ Numerical results } \\
\hline & & & \multicolumn{3}{|c|}{ Solid model } & \multicolumn{3}{|c|}{ Multi-fiber model } & \multicolumn{3}{|c|}{ Macro-element model } \\
\hline & Frequency & Period & Frequency & Period & $\begin{array}{c}\text { Reduced } \\
\text { period }\end{array}$ & Frequency & Period & $\begin{array}{c}\text { Reduced } \\
\text { period }\end{array}$ & Frequency & Period & $\begin{array}{c}\text { Reduced } \\
\text { period }\end{array}$ \\
\hline $1^{\mathrm{st}}$ mode & $2.77 \mathrm{~Hz}$ & $0.36 \mathrm{~s}$ & $4.30 \mathrm{~Hz}$ & $0.23 \mathrm{~s}$ & $0.29 \mathrm{~s}$ & $3.69 \mathrm{~Hz}$ & $0.27 \mathrm{~s}$ & $0.34 \mathrm{~s}$ & $3.85 \mathrm{~Hz}$ & $0.26 \mathrm{~s}$ & $0.48 \mathrm{~s}$ \\
\hline $2^{\text {nd }}$ mode & $6.66 \mathrm{~Hz}$ & $0.15 s$ & $12.30 \mathrm{~Hz}$ & $0.08 s$ & $0.10 \mathrm{~s}$ & $10.31 \mathrm{~Hz}$ & $0.09 \mathrm{~s}$ & $0.11 \mathrm{~s}$ & $11.99 \mathrm{~Hz}$ & $0.08 \mathrm{~s}$ & $0.17 \mathrm{~s}$ \\
\hline
\end{tabular}

\subsection{Viscous damping}

Modeling damping in structural reinforced concrete elements remains a challenging problem. Considerable research has been devoted to a better representation of the energy 
dissipation in reinforced concrete. In this study we have used the classical Rayleigh damping matrix for dynamic analyses of multi-degree-of freedom systems. The coefficients $\alpha$ and $\beta$ were calculated according to first two frequencies of the frame using a critical damping of $\xi=$ $3.3 \%$ which was determined experimentally. Furthermore, for the linear dynamic analysis with modal projection, a modal damping was adopted for the two considered first modes.

\section{SEISMIC ANALYSES APPROACHES}

For all analyses, the time step is adopted to about 0.01 seconds. For non linear problems we have used the according implicit time integration scheme of Newmark. The explicit time integration scheme was adopted for the linear dynamic analysis with modal projection.

\subsection{Linear analyses}

In this part of the study we have tested two linear dynamic approaches; the first one is the traditional dynamic time-history analysis computed in time domain with a linear elastic stiffness matrix and an equivalent viscous damping matrix. The second approach is the linear dynamic analysis with modal projection used only for short and regular buildings. Forces and displacements are calculated using modal coordinates for each mode considered. In accordance to the EC8 recommendations [2] we have considered the first two modes. To keep conforming results, the square root of the sum of the squares method of modal combination, SRSS, was carried out in order to estimate values of global displacements and forces at modal base. Findings of linear approaches are discussed later.

\subsection{Non linear analyses}

Constitutive model for concrete under cyclic loading ought to take into account some observed phenomena such as cracking induced decrease in material stiffness, stiffness recovery which occurs at crack closure and inelastic strains simultaneously to damage. To simulate this behavior we have used a uniaxial damage model with two scalars variables in which shear is considered linear for multi-fiber discretization and Ottosen (Ottosen; 1990) model for the 3D discretization. Ottosen model is according to fictitious crack model approach and is well adapted for brittle material such as concrete.

Figure 7, presents results for non linear dynamic time history analysis. It shows the top displacement time histories for the three models of discretization confronted to the

experimental results. Also, Figure 8, gives relative displacement spectrum response for different models. 

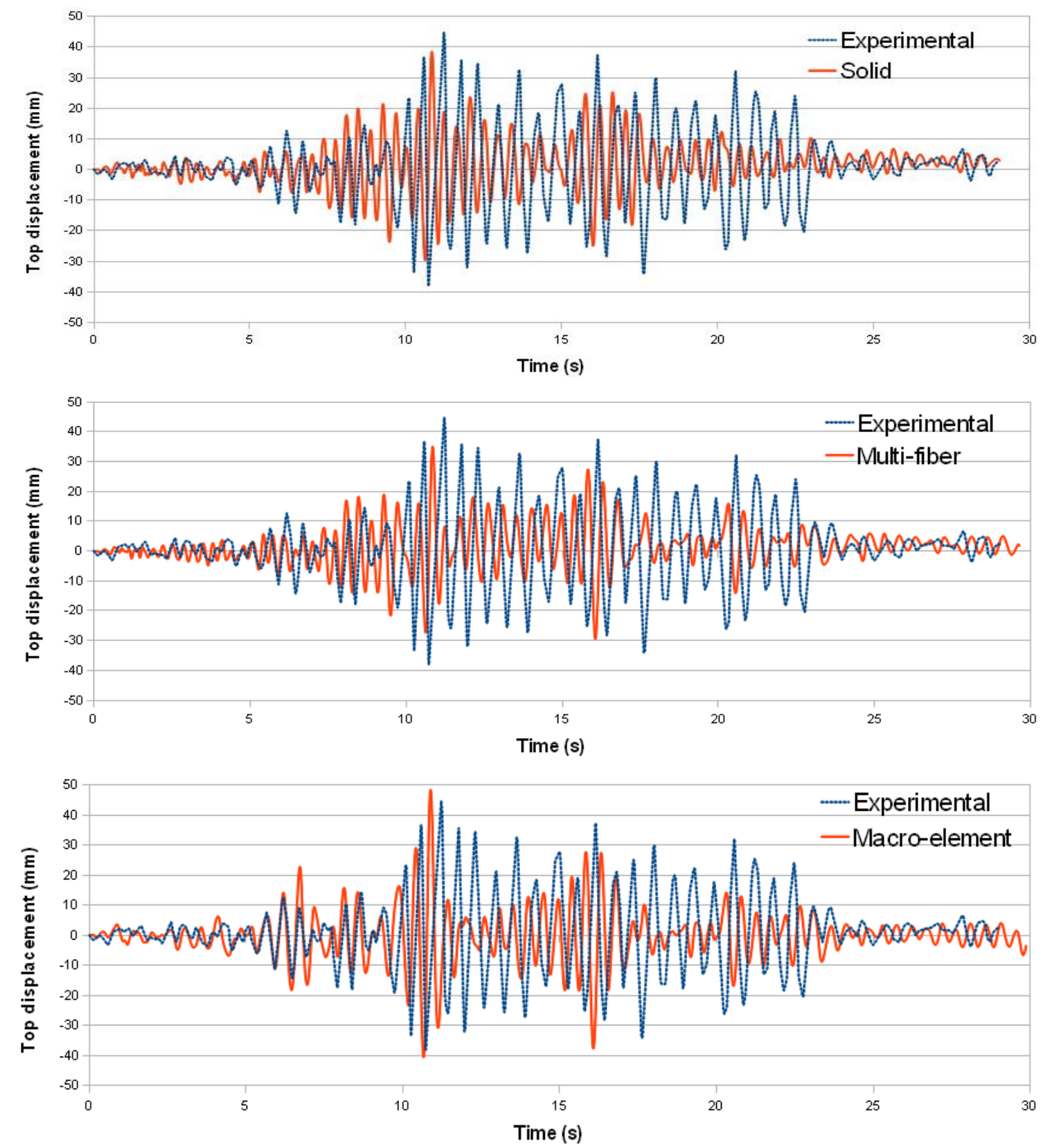

Figure 7. Top displacement time histories response.

The macro-element model, despite its simplicity, gives the best results. We found a good correlation in amplitude and phase before the concrete was damaged and a phase shifting when cracking of concrete because of the strong influence of shear deformation at the ends of beams [4] which are not taken into account numerically. The overall frame inelastic behavior is well reproduced for all model of discretization with an underestimate of displacement, Figure 8, and overestimation of acceleration. 


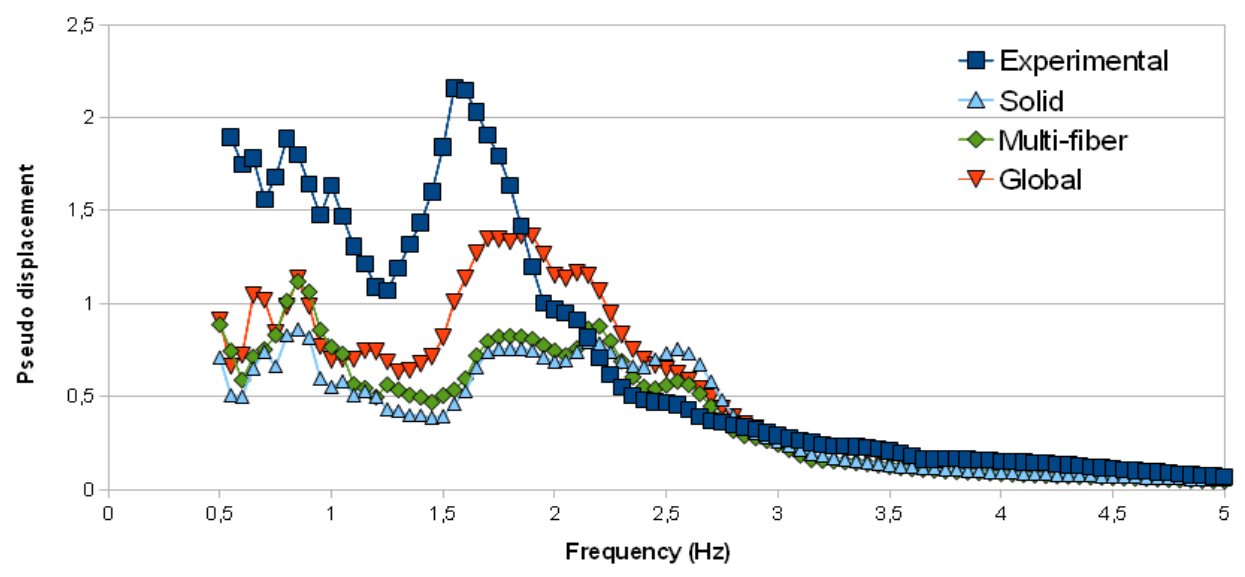

Figure 8. Displacement spectrum response, 5\% damping.

The static non linear approach adopted in this study, is the traditional pushover analysis. It is an approximate seismic approach through which an increasing lateral load of triangular or uniform type is applied over the height of the structure, until a target displacement is reached and/or the structure is collapsed. The pushover analysis searches the non-linear incremental solution iteratively, by solving the equilibrium equation $\{\mathrm{U}\} .[\mathrm{K}]=$ $\{\mathrm{F}\}$, where $\{\mathrm{U}\}$ is the displacement vector, $[\mathrm{K}]$ is the non-linear stiffness matrix and $\{\mathrm{F}\}$ represents the lateral force witch has a triangular form and is calculated according the European norm Eurocode 8 [2].

The pushover analysis permits estimating the sequence of yielding and failure at member and structural level as well as the progress of the overall strength capacity of the frame. Figure 9, shows the capacity curves of the structure for different models of discretization. It represents the horizontal forces of the base nodes or base shear versus the displacement of the top storey. The gradually softening response is simulated reasonably well for the global and semi-local model, although the response of solid model tends to be somewhat stiffer. The experimental capacity curve represents the envelop curve of the global hysteretic behavior of base shear - top floor relative displacement obtained experimentally during seismic test.

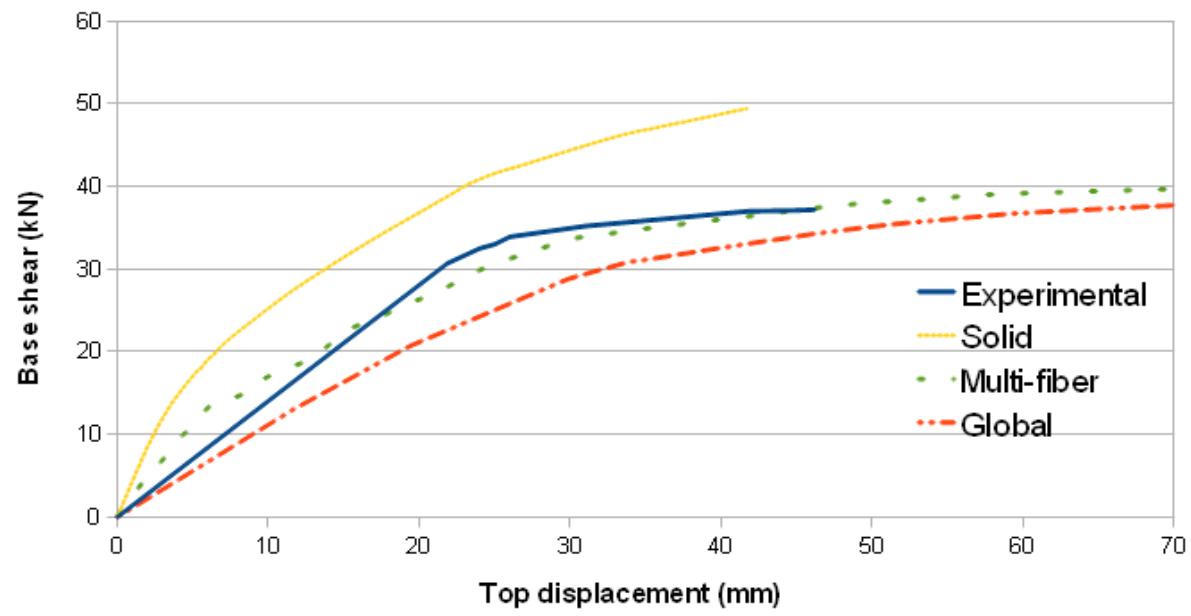

Figure 9. Base shear versus global structural drift. 
The nonlinear static procedure is increasingly used to establish the estimations of seismic demands for existing building structures. It is, however, restricted with a single-mode response. According to the EC8 [2] recommendations we have obtained the following results to predict the seismic demand for the studied frame:
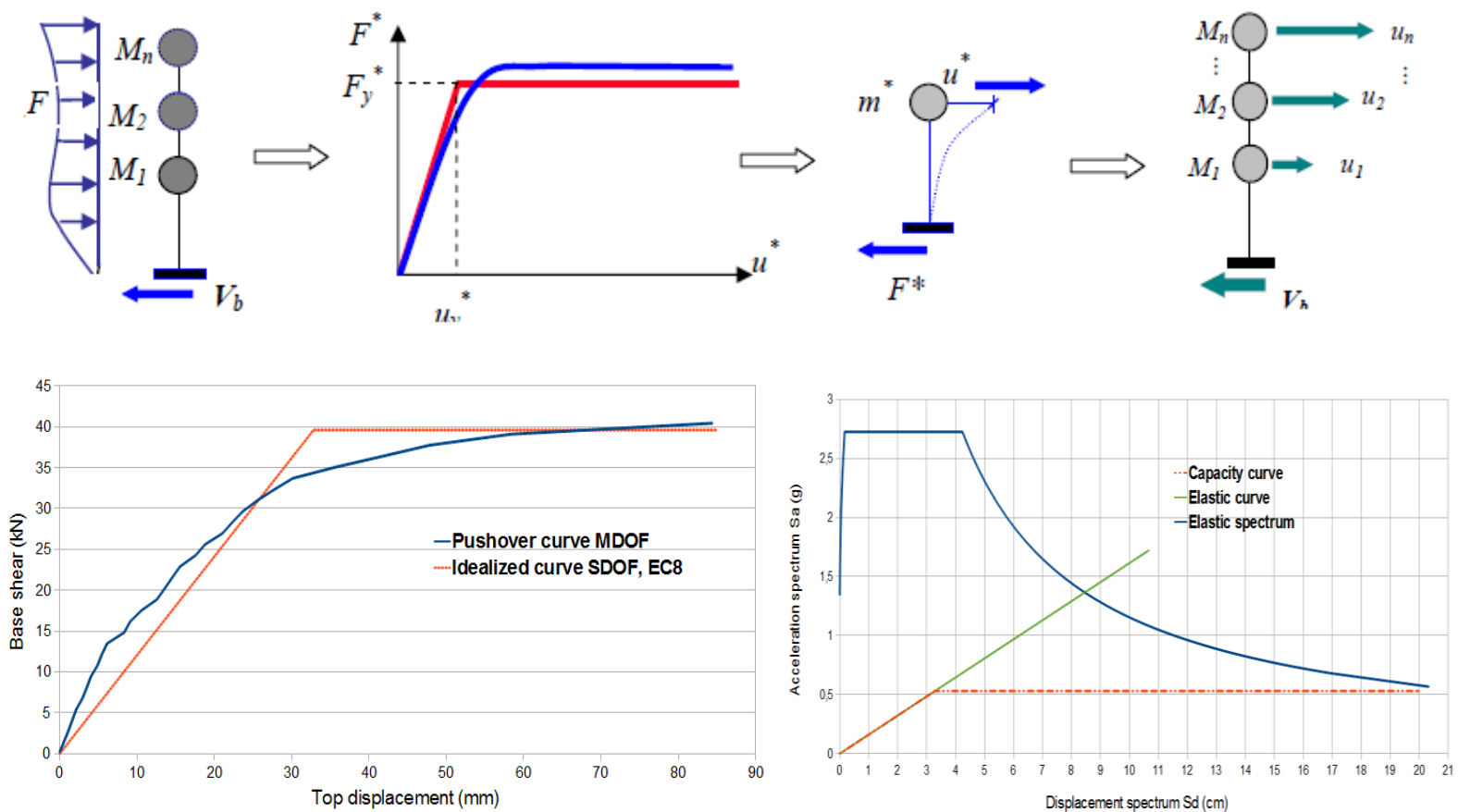

Figure 10. Process of transformation of MDOF system to SDOF system.

Table 2. Results of traditional pushover analysis.

\begin{tabular}{|l|l|l|}
\hline \multicolumn{1}{|c|}{ Parameters } & Multi-fiber model & Global model \\
\hline Ductility & 2.58 & 1.96 \\
\hline Elastic period for equivalent system SDOF & $0.5 \mathrm{~s}$ & $0.6 \mathrm{~s}$ \\
\hline Acceleration at yield point & $0.53 \mathrm{~g}$ & $0.539 \mathrm{~g}$ \\
\hline Displacement at yield point & $32.84 \mathrm{~mm}$ & $48.91 \mathrm{~mm}$ \\
\hline Maximum displacement for equivalent system SDOF & $85.32 \mathrm{~mm}$ & $93.21 \mathrm{~mm}$ \\
\hline Real maximum displacement for MDOF & $106.65 \mathrm{~mm}$ & $116.80 \mathrm{~mm}$ \\
\hline Real base shear for MDOF & $49.45 \mathrm{kN}$ & $49.90 \mathrm{kN}$ \\
\hline
\end{tabular}

Regarding linear analyses of different mesh model we found that the response of structure is strongly underestimated for the displacement and acceleration. It can be explained by the high inelastic behavior of the structure witch are neglected for both analyses linear dynamic time-history and dynamic with modal projection. Moreover, for the global discretization we can see a good correlation between response of the linear and non linear dynamic approaches due to exploitation of behavior parameters issued from experimental findings witch include non linear effects and loss of stiffness frame. 


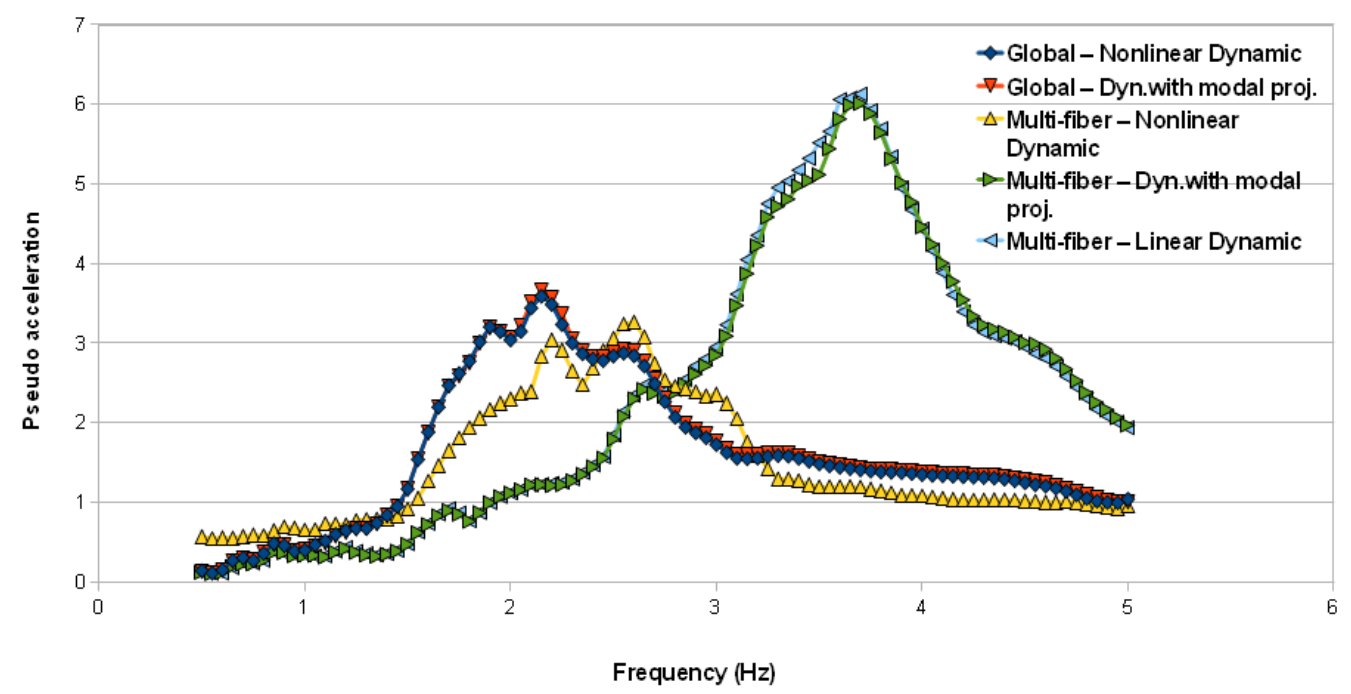

Figure 11. Absolute acceleration spectrum response, 5\% damping.

\section{SUMMARY OF FINDINGS AND CONCLUDING REMARKS}

This work deals a seismic behavior of a two-half scale reinforced concrete frame using different seismic approaches (static and dynamic, linear and non linear) applied to different multi-scales finite element discretization (Solid, multi-fiber and global). Aiming to assess the performance of each approach, numerical findings are confronted to the experimental results obtained from shake table test of studied frame.

The macro-element model gives the best overall results in linear and nonlinear analyses by reason that all behavior parameters of $\mathrm{RC}$ are introduced from the results of the experimental study including the phenomenon of damage and loss of stiffness.

For multi-fiber model the mechanical behavior could be improved by including inelastic shear effects. A refined mesh would have given better seismic response of the frame for the solid model but it has the disadvantage on the cost of analysis. It should be noted also that a refine mesh can causes an excessive localization of concrete damage.

Furthermore, it is noticed that in all studied models, the loss of stiffness due to shear stress was not considered at joints beam / column, which represent the most vulnerable parts of the structure, hence the underestimation of displacement and overestimation of the acceleration. Moreover, a review on the cost of each study was established in particular the computation time where we noticed a reduction in simulation time by $50 \%$ for the multi-fiber model and $95 \%$ for the global model compared to the refined 3D model. In the future, a particular attention will be focused to the macro-element approach because of the simplicity of its implementation and reliability of its results considered the most suitable for sensitivity and vulnerability analyses. For example, in the following work we would try to enhance the existing macro-models for shear wall taking into account 3D effects and the coupling phenomena of different degrees of freedom such as axial effort-flexion and/or bi-flexion with a particular attention to keep a good report cost/reliability.

\section{REFERENCES}

[1] Combescure D., "Modélisation des structures de génie civil sous chargement sismique à l'aide de castem 2000”. Rapport DM2S, CEA, REF. SEMT/EMSI/RT/01-008/A, 2001. 
[2] Eurocode 8. "Design of structures for earthquake resistance - Part 1: General rules, seismic actions and rules for buildings". NF EN, 1998-1, September 2005.

[3] Filiatrault A., Lachapelle E., Lamontagne P., "Seismic performance of ductile and nominally ductile reinforced concrete moment resisting frames. I. Experimental study". Can. J. Civ. Eng. 25: 331-341, 1998.

[4] Filiatrault A., Lachapelle E., Lamontagne P., "Seismic performance of ductile and nominally ductile reinforced concrete moment resisting frames. II. Analytical study". Can. J. Civ. Eng. 25: 342-352, 1998.

[5] Lachapelle E., "Étude du comportement sismique d'une ossature en béton armé à ductilité nominale R=2”. PFE. Ecole Polytechnique de Montréal, 1997. 